\title{
MERMAID BABY IN TWIN PREGNANCY
}

Alpana Singh ${ }^{1}$, Dipanwita Duttaㄹ, Sweta Lal'3 ${ }^{3}$ Rachna Agarwal ${ }^{4}$, Gita Radhakrishnan ${ }^{5}$

\section{HOW TO CITE THIS ARTICLE:}

Alpana Singh, Dipanwita Dutta, Sweta Lal, Rachna Agarwal, Gita Radhakrishnan. "Mermaid Baby in Twin Pregnancy". Journal of Evolution of Medical and Dental Sciences 2014; Vol. 3, Issue 11, March 17;

Page: 2907-2909, DOI: 10.14260/jemds/2014/2223

ABSTRACT: Sirenomelia, alternatively known as mermaid syndrome is a very rare congenital anomaly in which the legs are fused together, giving the appearance of a mermaid's tail. Till date less than 60 cases had been reported. We came across a twin pregnancy in which a normal female baby and another mermaid baby was delivered. The rarity and uniqueness of the syndrome prompted us to report the case.

KEYWORDS: Sirenomelia, Mermaid syndrome, Twin pregnancy, Congenital anomaly.

INTRODUCTION: Mrs. X 22 years old, G2P1L1 was a booked case and had a 2 years old normal child. She had normal antenatal follow-up with twin pregnancy. In her past medical history, she was not diabetic and did not have any chronic illness. Her 16 weeks scan showed diamniotic-monochorionic twin pregnancy and no obvious congenital anomalies in both fetuses. Her other antenatal investigations were normal. She came in labor at 34 weeks 5 days period of gestation and delivered vaginally. First baby which was abnormal 900 gems with sirenomelia in gasping condition and second was $2.2 \mathrm{~kg}$ normal female baby with normal APGAR. Cardiopulmonary resuscitation was done for first baby but could not be revived. Placental was single and normal.

Morphological abnormalities present in first baby were (Fig. 1):

- Single fused lower limb with no feet (symmelia apus)

- Absent external genitalia

- Imperforate anus

- Absence of urinary meatus

- Distended abdomen

- Deformed left upper limb

- Potter's face (ocular hypertelorism, low-set ears, receding chin and flattening of nose)

- Single umbilical artery

Autopsy was not done in our case as the family did not give consent for the same.

DISCUSSION: Sirenomelia sequence also known as "mermaid syndrome" is a rare (0.8 to 4.2 / 100 , 000 births) and mostly lethal congenital anomaly characterized by fusion of lower extremities or single lower limb, bilateral renal agenesis with absent or hypoplastic renal arteries, oligohydramnios, absence of urinary bladder and rectum, imperforate or absent anus, blind colon, absent internal and external genitalia, lumbosacral vertebral anomalies.

This anomaly predominantly affects male fetus (sex ratio 2.7:1). ${ }^{1}$ It has a strong association with maternal diabetes, where the relative risk is $1: 200-250$ and upto $25 \%$ of fetus with this anomaly will have diabetic mothers. ${ }^{2}$ 
$20 \%$ of cases are from twin pregnancy. There is a 100-150 times increased risk in monozygotic twins, but no such association has been found in cases of dizygotic twins. The etiopathogenesis of this syndrome is controversial and numerous theories have been proposed to explain its origin such as vascular steal theory as proposed by Stevenson et al, 1986,3 part of VACTREL syndrome, pressure theory. Some consider it to be the most extreme form of caudal regression syndrome.

Sirenomelia has been classified on the basis of number of fused bone by Stocker and Heifetz ${ }^{4}$ into seven types and based on number of feet. Our case is that of symmelia apus (fused on femur and tibia and no feet).

Prenatal diagnosis of this condition is accomplished by sonography. In sirenomelic fetus, bilateral renal agenesis causes severe oligohydramnios thus limiting proper evaluation of limbs in second and third trimester. However, in earlier gestation, the amniotic fluid volume is sufficient to detect abnormal lower limbs. ${ }^{5}$ recently; color Doppler sonography has been reported to be useful in the diagnosis by visualization of fetal vasculature. It reveals the origin of aberrant vitelline artery that continues as single umbilical artery. The distal aorta may be atretic or hypoplastic, iliac and femoral arteries may not be seen. ${ }^{6}$

Thus, the prenatal diagnosis is best made by combination of ultrasound features along with color doppler findings. Alternatively, MRI can be used because it is less hampered by oligohydramnios and permits evaluation of visceral lesions but it is not easily available.

Sirenomelia carries a very poor prognosis with most infants dying within 5 days of life. Survival is largely dependent on the extent of visceral anomalies such as renal agenesis/dysgenesis. The management is difficult and expensive with surgical and medical modalities, aimed at maintaining adequate renal function and are associated with unpredictable and mediocre results. ${ }^{7}$ Hence, in case of antenatal diagnosis, a voluntary termination of pregnancy is advisable. Most likely it was missed in routine scan, so scan should be done by expert sonologist. Aim should be an early prenatal diagnosis by first trimester scan to minimize the physical and psychological trauma related to the termination of pregnancy at advanced gestation.

\section{REFERENCES:}

1. Valenzano M, Paolitti R, Rossi A, Farinini D. Sirenomilia - pathological features, antenatal ultrasonographic clues and a review of current embryogenic theories. Hum Reprod Update 1999:5(1):82-86.

2. Davari F, Googol N, Kaveh M. Sirenomilia in an infant of a diabetic mother. Acta Medica Iranica 2003; 41(1):69-72.

3. Stevenrson RE, Jones KL, Philan MC, Jones MC, Barr N Jr, Clericuzio C et al. Vascular steal: the pathogenic mechanism producing sirenomelia and associated defects of the viscera and soft tissue. Peadiatrics 1986; 78(3):451-457.

4. Stocker JT, Heifetz SA. Sirenomelia: A morphological study of 33 cases and review of literature. Perspect Peadiatr Pathol 1987; 10:7-50.

5. Chenoweth CK, Kellog SJ, Yousef MM. Antenatal sonographic diagnosis of sirenomeila. J Clin Ultrasound 1991; 19(3):167-71.

6. Sepulveda W, Romero R, Pryde PC, Wolfe HM, Addis JR, Cotton DB. Prenatal diagnosis of sirenomelia with colour Doppler ultrasonography. Am J Obstet Gynecol 1994; 170:1377-9. 


\section{CASE REPORT}

7. Fa dhlaui A, Khrouf M, Gaigi S, Zhioua F, Chakee A. The sirenomeila sequence: A case history. Clin Med Insights Case Rep 2010; 3: 41-49.

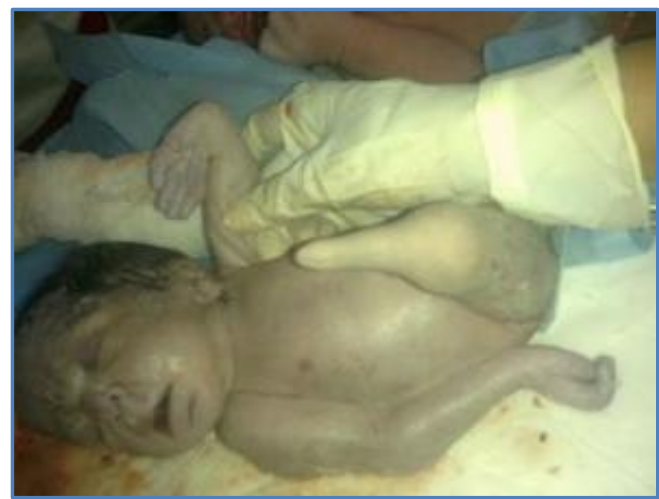

Figure 1: Photograph showing single fused lower limb with no feet (symmelia apus), deformed left upper limb and Potter's facies

\section{AUTHORS:}

1. Alpana Singh

2. Dipanwita Dutta

3. Sweta Lal

4. Rachna Agarwal

5. Gita Radhakrishnan

\section{PARTICULARS OF CONTRIBUTORS:}

1. Assistant Professor, Department of Obstetrics and Gynaecology, University College of Medical Sciences and Guru Teg Bahadur Medical College, Delhi.

2. Senior Resident, Department of Obstetrics and Gynaecology, University College of Medical Sciences and Guru Teg Bahadur Medical College, Delhi.

3. Senior Resident, Department of Obstetrics and Gynaecology, University College of Medical Sciences and Guru Teg Bahadur Medical College, Delhi.
4. Associate Professor, Department of Obstetrics and Gynaecology, University College of Medical Sciences and Guru Teg Bahadur Medical College, Delhi.

5. Director Professor, Department of Obstetrics and Gynaecology, University College of Medical Sciences and Guru Teg Bahadur Medical College, Delhi.

\section{NAME ADDRESS EMAIL ID OF THE CORRESPONDING AUTHOR:}

Dr. Sweta Lal,

D3, University College of Medical Sciences and Guru Teg Bahadur Hospital,

Residential Complex, Dilshad Garden,

Delhi - 95.

E-mail: drsweta2004@gmail.com

Date of Submission: $17 / 02 / 2014$.

Date of Peer Review: 18/02/2014.

Date of Acceptance: 26/02/2014.

Date of Publishing: 14/03/2014. 